WRI-97-R006

\title{
ACTIVITIES TO SUPPORT THE LIQUEFIED GASEOUS FUELS SPILL TEST FACILITY PROGRAM
}

Final Report

By

David Sheesley

S. Bruce King

Thayne Routh

March 1997

Work Performed Under Contract DE-AC01-91FE62302

For

U.S. Department of Energy

Office of Nonproliferation and National Security

Washington, D.C.

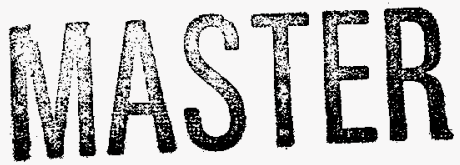

By

Western Research Institute

Laramie, Wyoming 


\section{DISCLAMIER}

Portions of this document may be illegible in electronic image products. Images are produced from the best available original document. 


\section{DISCLAIMER}

This report was prepared as an account of work sponsored by an agency of the United States Government. Neither the United States Government nor any agency thereof, nor any of their employees, make any warranty, express or implied, or assumes any legal liability or responsibility for the accuracy, completeness, or usefulness of any information, apparatus, product, or process disclosed, or represents that its use would not infringe privately owned rights. Reference herein to any specific commercial product, process, or service by trade name, trademark, manufacturer, or otherwise does not necessarily constitute or imply its endorsement, recommendation, or favoring by the United States Government or any agency thereof. The views and opinions of authors expressed herein do not necessarily state or reflect those of the United States Government or any agency thereof. 


\section{TABLE OF CONTENTS}

LIST OF TABLES AND FIGURES ........................................................................... iii

EXECUTIVE SUMMARY ........................................................................................ iv

INTRODUCTION

POTENTIAL FOR ACCIDENTAL RELEASES ........................................................ 4

1986 SARA LANGUAGE-BASIS FOR DOE TASKS IN THE

WRI STATEMENT OF WORK

WRI ACCOMPLISHMENTS UNDER THE ORIGINAL DOE-FE CONTRACT ............... 10

WRI ACCOMPLISHMENTS UNDER THE REPORTED CONTRACT ............................. 12

WORK RELATED TO THE 1986 SARA TASKS......................................................... 16

ANTICIPATED REQUIREMENTS FOR FUTURE ACTIVITIES ................................. 21

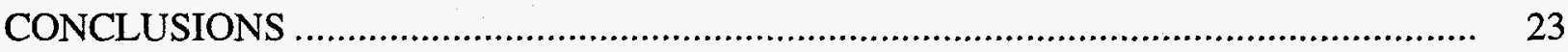

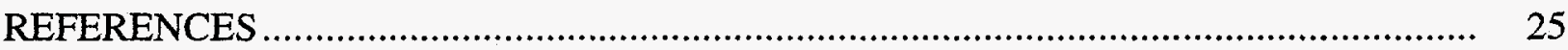




\section{LIST OF TABLES}

Table

1

Releases of Top 25 Chemicals in 1990

Page

Future Needs

8

2

LIST OF FIGURES

Figure

1

Kit Fox Field Experiment Structure

Page

20 


\section{EXECUTIVE SUMMARY}

This final report to the U.S. Department of Energy (DOE) provides a summary of the activities conducted by and the accomplishments of Western Research Institute (WRI) under the five-year contract DE-AC01-91FE62302. The basis for the scope of work for the contract was the 1986 Superfund Amendment and Reauthorization Act (SARA), Section 118(n) language. Section 118(n) mandated the investigation of the current technology available to maintain public safety in the occurrence of an accidental release of hazardous materials, either from a fixed facility or during a transportation accident. Specific Congressional direction was given for the transfer of the technology to the public sector so that emergency response personnel would have the latest information, procedures, predictive capabilities, and mitigation techniques available to best protect the public and themselves.

Historically, within the chemical and petrochemical industries there have been numerous accidental releases, as there have been within the transportation industry, which conveys these hazardous materials. Previous research programs have been sponsored by DOE to address some of the issues regarding liquefied fuels, primarily liquefied natural gas (LNG). A great deal of this work was conducted at the DOE owned and operated facility located at the Nevada Test Site, called the Liquefied Gaseous Fuels Spill Test Facility (LGFSTF). The mission of the facility and its research program has been expanded to include more than just liquefied fuels. The LGFSTF has been charged with providing a location to investigate other hazardous materials, whether flammable, explosive, or toxic. The LGFSTF was specifically designated as the location for the 1986 SARA Section 118(n) research program to be conducted.

The description of the WRI activities and accomplishments under this contract are discussed in the context of WRI's overall commitment to the development of a sound scientific basis for developing technology that can be put in the hands of the public to deal more effectively with real-world accidental releases of hazardous materials. This commitment encompasses a previous contract with the DOE under which WRI provided support to the LGFSTF spill program through a number of activities. These activities have included accident investigations, archiving LGFSTF spill data, developing a bibliography of pertinent research, assembling a mailing list of individuals and organizations involved in related and supporting research, and assisting DOE in its outreach program to publicize the capabilities of and test results of the LGFSTF.

Under the reported five-year contract, WRI has continued some of these activities by increasing the amount of data archived, making a portion of the data available to the public via either a bulletin board system (BBS) or the Internet, increasing the size of the bibliography and mailing list, and continuing to support the public awareness of the LGFSTF and its resources. 
Based on the language of the 1990 Clean Air Act Amendments (CAAA), which complements that of the SARA, WRI has conducted field research activities of hazardous chemical releases sponsored by the Environmental Protection Agency (EPA). These experiments have been collaborative programs conducted with EPA, DOE, and industrial participants and are directly related to the 1990 CAAA, Section 112(r), Risk Management Planning (RMP) regulations scheduled for implementation in 1999. Separately, with in-house funding, WRI has effected technology transfer by developing a palmtop computer application that places in the hands of emergency response personnel the information necessary to deal with hazardous material spills so as to maintain the safety of the public and response personnel. 


\section{INTRODUCTION}

Approximately a hundred years ago the petrochemical industry was in its infancy, while the chemical industry was already well established. Today, both of these industries, which are almost indistinguishable, are a substantial part of the makeup of the U.S. economy and the lifestyle we enjoy. It is difficult to identify a single segment of our daily lives that isn't affected by these industries and the products or services they make available for our use. Their survival and continued function in a competitive world market are necessary to maintain our current standard of living. The occurrence of accidents in these industries has two obvious effects: (1) the loss of product during the accident and future productivity because of loss of a portion of a facility or transport medium, and (2) the potential loss of life or injury to individuals, whether workers, emergency responders, or members of the general public. Another effect, although not as immediately evident, is the risk of public outcry and disillusionment in the perceived balance of advantages and disadvantages of having these industries operating in our society. If a disaster such as the December 1984 Bhopal, India, methyl isocyanate release occurred in this country, the consequences for the facility involved and the long-term damage to the industry in general would be devastating.

Government agencies, industry, and Congress recognize that a modern society, such as in the U.S., which enjoys the benefits and lifestyle derived from using materials such as fuels, chemicals, and explosives, must also learn to deal with the potential for accidents involving these substances. The public expects that proper measures, whether through regulations or industry standards, be undertaken to minimize the potential for accidents and that proper procedures be available to maintain public safety when an accident does occur. The chemical and petrochemical industries, through the American Institute of Chemical Engineers (AIChE) Center for Chemical Process Safety (CCPS), has addressed a number of operating procedures and practices to minimize the potential for accidents. This initiative has been in conjunction with the Occupational Health and Safety Administration (OSHA) development of regulations and the industry's Process Safety Management (PSM) development of practices. These activities have focused primarily on the prevention and minimization of industrial accidents, while other activities by industry and governmental agencies to maintain public safety have begun addressing the procedures to enact in the event of an accident.

Recognizing these issues, Congress has directed various federal agencies to address the regulation of certain activities of private industry and public agencies that may affect individuals' safety and health. This can be seen in the increased authority of the Environmental Protection Agency (EPA) since its creation during the early 1970s, when environmental issues prompted

public concern. The creation of the EPA has been augmented by passage of the original Superfund legislation, OSHA mandates addressing worker safety, the enactment of the 
Comprehensive Environmental Response, Compensation, and Liability Act (CERCLA), the Emergency Planning and Community Right-to Know Act of 1986, the 1986 SARA Title III formation of local emergency planning commissions (LEPCs), State Emergency Management Agencies (EMAs), and State Emergency Response Commissions (SERCs) to assemble a system of identification of local facilities and transportation routes where fuels and other chemicals or hazardous materials are present, and passage of the 1990 Clean Air Act Amendments (CAAA). In addition, the Federal Emergency Management Agency (FEMA) organized the regions to implement emergency response in the regions (grants and training) and adopted the position that FEMA is responsible for readiness, response, and recovery during natural and man-made disasters. FEMA endorsed a perspective on toxic and flammable vapor dispersion research in 1993, acknowledging that this research is in the area of readiness and response.

A specific example of these activities comes from the late 1970s when increasing prices for oil imports suggested that imported liquefied natural gas (LNG) would become a major component of the U.S. energy mix, and the Department of Energy (DOE) addressed the potential for accidental release of LNG during transfer or transportation. A research program jointly sponsored by the U.S. Department of Energy Office of Fossil Energy (DOE-FE) and the Gas Research Institute (GRI) and conducted by the Naval Weapons Center (NWC) and the Lawrence Livermore National Laboratory (LLNL) was developed to study the behavior of massive releases of LNG to simulate what might happen during an accidental release. The initial experiments, referred to as the Burro and Coyote field tests, were conducted at the China Lake Naval Weapons Center in California. The facilities used were temporary, and in 1983 Congress provided funding to build a permanent test facility, the Liquefied Gaseous Fuels Spill Test Facility (LGFSTF), that was later constructed at the Frenchman Flat dry lake bed located on the Nevada Test Site. In acknowledgment of the increaing potential for accidental releases of hazardous substances other than liquefied gaseous fuels, the mission of the LGFSTF was broadened to include the investigation of the behavior of accidental releases of additional substances. To this end, the LGFSTF has been used to study the release of other hazardous materials, including ammonia, nitrogen tetraoxide, chlorine, hydrogen fluoride, and chlorosilanes.

In 1986, Congress passed the Superfund Amendment and Reauthorization Act (SARA). Section 118(n) of the language authorizes the Secretary of the United States Department of Energy to carry out a program of testing and evaluation of technologies that may be utilized in responding to spills of liquefied gas and other hazardous substances that threaten public health or the environment. In addition, the SARA language outlines how this technology is to be transferred to the public sector and mandates that this program of testing and evaluation of technologies is be carried out at the LGFSTF. Finally, the legislation directs the Secretary of Energy to enter into contracts with and provide grants for a nonprofit organization in Albany 
County, Wyoming, that is capable of providing the necessary technical support and that is involved in environmental activities related to emergencies involving hazardous substances.

In 1988, the DOE-FE entered into the initial one-year contract with Western Research Institute (WRI) that addressed a portion of the direction given in the 1986 SARA language. In 1991, DOE-FE entered into the current contract with WRI, which provided for a one-year Base contract and four renewable option years to again address the 1986 SARA directives. In October 1995, the management of the LGFSTF was transferred to the Office of Nonproliferation and National Security (NN-60), as was the management of the existing WRI five-year contract. The scope of work included additional tasks related to the support of the DOE Spill Test Program. The DOE-assigned tasks have addressed only a portion of the 1986 SARA-directed tasks, primarily as a result of the level of funding. These tasks have focused on the archiving, documenting, and accessibility of the spill test facility (STF) data base acquired from LLNL and expanding the scope of the spill-related bibliography. This report discusses the scope of work outlined in the congressional language, the assigned tasks that WRI has been delegated to address and the corresponding results. These results are provided in the context of other WRI activities related to these tasks and the anticipated requirements for future activities.

Similar in scope and intent to the SARA mandates, the 1990 CAAA authorized the Secretary of Energy to develop emergency response technologies via Wyoming and Nevada notfor-profit research institutes because the organizations of each state were not obligated to either the regulator or the industry. This plan was sidetracked when implementation was placed in the EPA Office of Research and Development (ORD). The budget for the scope of work was authorized at $\$ 3$ million a year. The statement of work for Emergency Response Technology was to include a laboratory and field research program intended to: (1) develop improved predictive models, (2) evaluate existing and future atmospheric dispersion models, and (3) evaluate the effectiveness of hazard mitigation and emergency response technology. This research program was to have access to the LGFSTF to conduct these activities.

In July 1993, the first EPA-ORD CAAA sponsored dispersion experiments were conducted at the LGFSTF by WRI with Desert Research Institute (DRI) of Reno, Nevada. These experiments laid the groundwork for a broad scope of work to address the Congressional intent. The large field demonstration project was sponsored by DOE, EPA, and the Petroleum Environmental Research Forum ${ }^{1}$ (PERF) Project 93-16 in August and September 1995. The data

\footnotetext{
${ }^{1}$ The 10 companies making up the Petroleum Environmental Research Forum (PERF) are Allied Signal, Corporation; Amoco Corporation; Chevron Research and Technology Co.; CITGO Petroleum Corporation; Clark Oil and Refining Co.; Exxon Research and Engineering Co.; Marathon Corporation; Mobil Research and Development Co.; Phillips Petroleum Co.; and Shell Research \& Development Co.
} 
was acquired to assist regulators and industry in better understanding the behavior of dense gas releases under 'worst-case' conditions. An additional set of evaporation experiments were conducted in the LGFSTF wind tunnel by WRI in March-April 1995, sponsored by the EPA's CAAA research program. These experiments were conducted to better define the source strength of chlorine and ammonia, two widely produced, used, and transported hazardous chemicals.

WRI's in-house funding of a mechanism to transfer relevant technology to the emergency response sector of the public has resulted in the development of a commercial product in the form of a palmtop computer. The software application on the palmtop platform provides emergency personnel with the necessary resources and information to deal with either fixed facility or transportation-based accidents involving chemical spills so that they can maintain the safety of the public and emergency personnel.

\section{POTENTIAL FOR ACCIDENTAL RELEASES}

An analysis by the National Environmental Law Center and the U.S. Public Interest Research Group (Tickner and Gray, 1994) of the EPA's 1988-1992 Emergency Response Notification System (ERNS) data base showed that 680 million pounds of toxic chemicals were released into the environemnt as a result of accidents in the United States. While this quantity would appear substantial, it represents a gross underestimate because one-third of the notifications offered no estimate whatsoever of the quantity released. Tickner and Gray also pointed out that while the ERNS is the largest national dataset on accidents, it is incomplete and doesn't represent an accurate picture of the accidents occurring in the United States. As an example, a study by the New York State Attorney General's Office identified 3,496 accidents involving toxic chemicals in New York State from 1988 to 1990 compared to only 466 accidents (13\%) reported to the ERNS during the same period. Therefore, the 680 million pounds during 1988-1992 may only be a small portion of the actual toxic chemical releases due to accidental spills for those five years. The chemicals that were involved in the most cases of immediate injury, evacuation, or death were chlorine, ammonia, sulfuric acid, and hydrochloric acid. About $75 \%$ of the toxic chemical releases occurred at plant sites or buildings, $3 \%$ were associated with pipelines, and most of the rest occurred as the result of transportation accidents.

A hydrogen fluoride (HF) release occurred on October 30, 1987, at the Marathon Corporation refinery at Texas City, Texas, that might have been catastrophic had it not been for favorable winds. Equipment dropped from a crane sheared two pipes on top of a 12-ft diameter, 20 -ft high pressurized tank containing an estimated 30,000 pounds of liquid HF capped with isobutane. The contents escaped over a period of two hours, resulting in a plume of HF 2 to 3

miles long and 0.5 to 1.0 miles wide, which led to the evacuation of 3,000 people and the 
treatment of 800 people for breathing disorders and skin problems. The evacuation was criticized by Dr. Fred Miller of the Environmental Policy Institute, who issued a public statement that based on HF spill tests conducted at the Nevada Spill Test Facility, the evacuation distance downwind should have included a semicircle of 7 miles or 70,000 people.

During August 1986, Amoco (Blewitt et al, 1988) had conducted spill tests of liquid HF and found that the HF liquid was carried away quickly with the wind as a ground-hugging fine aerosol, much different than predicted by plume models. Amoco had shared the spill test results with the petroleum industry. Dr. Miller said that the results were not adequately communicated to local emergency response officials. If a pipe on the sides or near the bottom of the tank had been sheared, the entire tank contents would have escaped at once, and a disaster comparable to the 1984 methyl isocyanate spill in Bhopal, India, which killed 2,000 people, would have resulted.

Models were available for calculating the evaporation rate from a spilled pool. When spill tests were done at the Nevada Spill Test Facility in 1986, no liquid pool formed. Instead, the HF dispersed $20 \%$ as a gas and $80 \%$ as a ground-hugging aerosol carried with the wind. The HF gas also reacted readily with moisture in the air, forming a mist.

Other examples of chemical or petrochemical accidental releases were reported by The New York Times, June 19, 1991:

- Pampa, Texas, Nov. 14, 1987 - Butane and acetic acid leaked from a ruptured tank, forming a cloud of vapor that caught fire, destroying the Hoechst Celanese chemical plant, killing 3 workers and injuring 35 people. Economic loss, including property damage, lost production, legal expenses and fines: $\$ 241$ million.

- Henderson, Nevada, May 4, 1988 - Fire and explosion destroyed a Pacific Engineering and Production Company plant that manufactured ammonium perchlorate, a component of rocket fuel. Two employees, including the plant manager, were killed, 350 people were injured, 17,000 people were evacuated from their homes, and property damage was found 12 miles from the plant. Economic loss: $\$ 75$ million.

- Norco, Louisiana, May 5, 1988 - An 8-in. pipe ruptured at a Shell Oil refinery, releasing a vapor cloud that ignited and exploded, killing 7 workers, injuring 42 , and causing property damage that resulted in 5,200 claims. Economic loss: \$327 million.

- Pasadena, Texas, October 23,1989 - A valve on a polyethylene reactor was left open at a Phillips Petroleum plastics plant, venting gases that caught fire and exploded with the force of 20,000 tons of TNT. Twenty-three workers died, 232 people were injured, and the plant was destroyed. Economic loss: $\$ 750$ to 1,000 million.

- Baton Rouge, Louisiana, December 24, 1989 - A pipeline operating at high pressure ruptured at the Exxon USA refinery, releasing a cloud of ethane and propane that exploded, killing 2 
workers, injuring 7 and causing property damage up to 6 miles away. Economic loss: $\$ 44.7$ million.

- Channelview, Texas, July 5, 1990 - An explosion in a compressor at a company owned by Atlantic Richfield killed 17 workers. Economic loss: $\$ 90$ million.

- Cincinnati, Ohio, July 19,1990 - A fire and explosion at the BASF coatings and ink plant resulted from the cleaning of a chemical reactor with volatile solvents. Two workers died, 80 people were injured, much of the plant was destroyed, and 162 buildings were damaged.

- Lake Charles, Louisiana, March 3, 1991 - A fire and explosion killed 6 workers, injured 12, and caused extensive damage at the Citgo Petroleum refinery.

- Corpus Christi, Texas, March 5, 1991 - Two workers died and 5 were injured when hydrofluoric acid vapors escaped from a gasoline blending unit at the Kerr-McGee Corporation's Southwestern Refinery.

- Port Lavaca, Texas, March 12, 1991 - An explosion in the ethylene oxide unit of Union Carbide's Seadrift plant killed 1 and injured 19. Economic loss: $\$ 50$ to 75 million.

- Sterling, Louisiana, May 1, 1991 - A fire in or near a compressor detonated nitro methane at the Angus Chemical Company plant, killing 8 workers, injuring 128 workers and residents, destroying much of the town's main business district, and leaving 30 families temporarily homeless. Economic loss: more than $\$ 110$ million.

- Henderson, Nevada, May 6,1991 - A pipe from a storage tank at the Pioneer Chlor Alkali plant leaked thousands of gallons of liquid chlorine in the middle of the night, causing evacuation, shutting down the city, and sending 55 people to hospitals for treatment of injuries, mostly breathing problems.

- Charleston, South Carolina, June 17, 1991 - An explosion and fire at the Albright \& Wilson Americas chemical plant killed 6 workers and injured 23 others, including 2 firefighters. The accident occurred one day after a week-long shutdown.

Toxic, flammable, and explosive chemicals are not the only reason for concern. Carbon dioxide is a dense gas and can accumulate in confined spaces, resulting in displacement of oxygen. Carbon dioxide can be released from natural sources in sufficient quantity such that the resulting dense gas plume causes death through asphyxiation. An example was the belching of Lake Nyos in Cameroon (Africa) on August 21, 1986, with the resulting carbon dioxide plume traveling down a river valley for a distance of $10 \mathrm{~km}$ killing 1,700 people and 3,000 cattle. Scientists following up on the Lake Nyos incident (Kling et al, 1987) estimated that $3 \mathrm{~km}^{3}$ of gas containing 98 to $99 \%$ carbon dioxide (balance methane, nitrogen, and oxygen) was released. Another incident, on August 15, 1984 at Lake Monoun, also in Cameroon, killed 37 people.

A Chemical Safety and Hazard Investigation Board has been established (CAAA, Section $112(\mathrm{r})(6))$, which investigates and reports to the public the circumstances and causes of any accidental release resulting in a fatality, serious injury, or substantial property damage. This board 
is also required to make a report to EPA and OSHA recommending regulations for preparation of risk management plans and to prevent accidental releases into the air, including mitigation of releases or spills. Chemical accidents resulting in public evacuation have demonstrated the need for risk management programs and communication to state and local agencies. These chemical accidents have also demonstrated the shortcomings of air dispersion models in predicting evacuation zones. For industry to remain competitive, models for risk assessment must be developed that provide more accurate source term definition and that account for variable terrain and obstacles.

The major provisions of Title III of the CAAA incorporate laws begun under the Emergency Planning and Community Right-to-Know Act of 1986, also known as Title III of the Superfund Amendments and Reauthorization Act (SARA III). The risk management plan and emergency response plan required by the CAAA are in addition to reporting requirements under the Emergency Planning and Community Right-To-Know Act of 1986. The CAAA legislation requires the EPA (based on the CAAA Section $112(\mathrm{r})(7)$ ) to issue regulations requiring owners or operators of facilities where regulated substances are manufactured or used to prepare risk management plans for the detection and prevention or minimization of accidental releases and to have in place emergency response plans, including material safety data sheets, inventories, and locations, for the mitigation of any release. This information is to be submitted to appropriate local emergency planning committees, the local fire department, and the state emergency response commission. There are also reporting requirements in case of a spill or accidental release.

Under the Emergency Planning and Community Right-to-Know Act of 1986 and under the Comprehensive, Environmental Response, Compensation, and Liability Act of 1980 (CERCLA), any spills of regulated chemicals exceeding threshold values must be reported to federal, state, and local governments, including the EPA. SARA requires industry and the DOE, and EPA, the Department of Transportation (DOT), and the Depatment of Defense (DOD) to report chemical inventory, and accidental spill or releases and established the process for reporting. (Chemical accidents are usually referred to as releases within the chemical industry.) This list of regulated chemicals is published in 40 CFR part 302, which is different from the list published as a requirement for developing risk management plans under the CAAA. The chemicals on the EPA list and their thresholds are published in 59 Fed. Reg., Jan. 31, 1994, p. 4477. EPA has estimated (Federal Register, Jan 31, 1994) that 118,000 facilities will be affected. The list includes 77 toxic substances, 63 flammable substances, and explosives (listed by DOT in Division 1.1 of 49 CFR 172.101). There is a real need to conduct spill testing to define chemical behaviors and to communicate spill test results to industry and local agencies responsible for risk management and emergency response plans. 
Table 1 presents the major chemicals spilled in 1990 arranged in alphabetical order, with total quantity spilled. Risk management plans are required under the CAAA for the top three chemicals (ammonia, hydrochloric acid, and sulfuric acid) listed in terms of total amount released.

Table 1. Releases of Top 25 Chemicals in 1990*

\begin{tabular}{|l|c|l|c|}
\hline Chemical & Millions of lb/yr & Chemical & Millions of lb/yr \\
\hline Acetaldehyde & 8.0 & Ethylene & 30.6 \\
\hline Acetone & 78.9 & Ethylene glycol & 10.7 \\
\hline Acetonitrile & 20.6 & Formaldehyde & 11.1 \\
\hline Acrylic acid & 21.9 & Hydrochloric acid & 160.4 \\
\hline Acrylonitrile & 7.9 & Manganese compounds & 7.2 \\
\hline Ammonia & 274.4 & Methanol & 65.5 \\
\hline Ammonium nitrate & 33.7 & Methyl chloride & 7.5 \\
\hline Ammonium sulfate & 10.3 & Nitric acid & 32.4 \\
\hline Carbon disulfide & 34.6 & Phosphoric acid & 11.0 \\
\hline Carbonyl sulfide & 16.8 & Propylene & 14.1 \\
\hline Chlorine & 7.0 & Sulfuric acid & 107.9 \\
\hline Chromium compounds & 7.9 & Toluene & 25.5 \\
\hline Dichloromethane & 18.7 & Total & $\mathbf{1 0 2 4 . 8}$ \\
\hline
\end{tabular}

*Chemical and Engineering News, Nov. 16, 1992

\section{SARA LANGUAGE- BASIS FOR DOE TASKS IN THE WRI STATEMENT OF WORK}

The basis for the original DOE Office of Fossil Energy and current DOE Office of Nonproliferation and National Security (DOE NN-60) statement of work for the five-year contract is the language in the 1986 Superfund and Reauthorization Act (SARA), PL 99-499, Section 118 , which is as follows:

\section{(n) SPILL CONTROL TECHNOLOGY.}

(1) ESTABLISHMENT OF PROGRAM. Within 180 days of enactment of this subsection, the Secretary of the United States Department of Energy is directed to carry out a program of testing and evaluation of technologies which may be utilized in responding to liquefied gaseous and other hazardous substances spills at the Liquefied Gaseous Fuels Spill Test Facility that threaten public health or the environment.

(2)TECHNOLOGY TRANSFER. In carrying out the program established under this subsection, the Secretary shall conduct a technology transfer program that, at a minimum -
(A) documents and archives spill control technology;
(B) investigates and analyzes significant hazardous spill incidents; 
(C) develops and provides generic emergency action plans;

(D) documents and archives spill test results;

(E) develops emergency action plans to respond to spills;

(F) conducts training of spill response personnel; and

(G) establishes safety standards for personnel engaged in spill response activities.

(3) CONTRACTS AND GRANTS. The Secretary is directed to enter into contracts and grants with a nonprofit corporation in Albany County, Wyoming, that is capable of providing the necessary technical support and which is involved in environmental activities related to such hazardous substance related emergencies.

(4) USE OF SITE. The Secretary shall arrange for use of the Liquefied Gaseous Fuels Spill Test Facility to carry out the provision of the subsection.

The following statement of work for contract DE-AC01-91FE62302 was provided in the original contract documentation:

1. Test and evaluate technologies which may be used to respond to liquefied gaseous and other hazardous substances spills that threaten public health or the environment.

2. Establish a technology transfer system and provide outreach related to facility activities that:

- documents and archives spill control technology;

- investigates and analyzes significant hazardous spill incidents;

- develops and provides generic emergency action plans;

- documents and archives spill test results;

- develops emergency action plans to respond to spills;

- conducts training of spill response personnel; and

- establishes safety standards for personnel engaged in spill response activities.

3. Establish a research and development testing program for use on a fee basis to:

- the public; and

- private sectors.

In December 1991, the Statement of Work for WRI was to assist DOE in establishing a technology transfer effort and to provide outreach related to LGFSTF activities that:

- documents and archives spill control technology

- investigates and analyzes significant hazardous spill incidents

- develops and provides generic emergency action plans 
- conducts training of spill response personnel

- establishes safety standards for personnel engaged in spill response activities.

The objective of the first year's effort of the contract was to establish a technology transfer and outreach system. The primary assignments on this task were:

1. Continue the work initiated under contract No. DE-AC01-88FE61472 to identify and assemble information judged to be pertinent to the nation's spill test research effort.

2. Continue to gather references and update the current bibliography of spill test data in a form that DOE can make available to the public.

3. Continue to collect hardcopies of all reports, published or unpublished, that will provide the necessary documentation to data sets.

4. Continue to establish and/or develop a complete set of LGFSTF-related data files of tests conducted by the Lawrence Livermore National Laboratory (LLNL) and to create a bibliography for each test series run by LLNL.

Because of the broad assignment of tasks and the inadequate level of funding, WRI never directly addressed the testing and evaluation of technologies that may be used in responding to liquefied gaseous and other hazardous substances spills under this five-year contract.

\section{WRI ACCOMPLISHMENTS UNDER THE ORIGINAL DOE-FE CONTRACT}

To describe the accomplishments of WRI during the reporting contract period, it is necessary to briefly describe some of the work completed under the previous contract with DOEFE (Sheesley and Diamond, 1980). This contract also provided support to the DOE-FE's LGFSTF spill program. In March 1988, the DOE Office of Fossil Energy entered into contract DE-AC01-88FE61472 with WRI, which first addressed the language in the 1986 SARA, Section $118(\mathrm{n})$. In summary, under this contract WRI:

1. Assisted DOE-FE in the development of a collaborative research program.

2. Conducted an investigation of accidental releases of hazardous chemicals that covered 123 separate incidents (Nordin and Sheesley, 1989).

3. Developed a bibliography of publications and reports pertaining to spills technology (Chilson, Sheesley and Diamond, 1989).

4. Received from LLNL in November 1989 a magnetic tape copy of the LLNL data base files developed from the China Lake and LGFSTF field experiments, which totaled $\sim 70 \mathrm{MB}$ of storage space.

Throughout the duration of this contract, WRI provided technical and analytical support to the DOE LGFSTF spill program as DOE-FE worked to develop a collaborative research 
program with EPA, the DOT, and industry (Leone, 1989 and Leone, 1990). These activities involved interacting with potential customers and disseminating to the public the capabilities of the LGFSTF and its testing program. These activities were continued into the new contract as described below when WRI was a cosponsor of the Spill Test Program Forum held in Las Vegas, Nevada, in June 1991.

It was concluded from the investigation of the 123 hazardous chemical accidents that the accidents and resulting toxic emissions were very diverse and were rarely describable by available plume dispersion models. In fact, dispersion models were used in only a few instances. Weak points were source term definition, inadequate or unknown meteorology at the time of the release, and the effect of real-world surface roughness (buildings or structures and surface topography) on plume dispersion. The models did not account for the effects of sprays, foams, or liquid caps placed on a second liquid to minimize evaporation nor other mitigation methodology used to minimize emissions.

The bibliography contained a compilation of $\sim 800$ separate reports and publications pertaining to the research programs conducted by DOE at the LGFSTF and the data bases generated during these field experiments. In addition, other research programs related to the LGFSTF spill program are reported in the literature. These include industrial studies, academic field investigations, and field investigations by other governmental agencies, laboratory experiments, model evaluations, and model development activities directed at improving the understanding and predictability of the emergency response technologies available to the public sector.

The existence of the LLNL spill program data base developed from the publicly funded research program conducted at the China Lake Weapons Center and the LGFSTF was deemed significant, and it was thought to be imperative that it be made available to those individuals and organizations conducting research on the behavior of chemical spills to improve emergency response technology. The accessibility of this data base had been limited in the past, and the 1986 SARA language was intended to change this. In November 1989, after many delays, LLNL made available to WRI a magnetic tape that contained the currently available version of the LLNL LGFSTF spill program data base. The $\sim 70$ megabyte data base comprised over 1,000 files for the Burro, Coyote, Desert Tortoise, Eagle, Falcon, and Goldfish dispersion experiments. With the limited funding remaining from the contract, WRI undertook a review of these data files to better understand what type of accompanying documentation would be required when they were made available to the public sector. 


\section{WRI ACCOMPLISHMENTS UNDER THE REPORTED CONTRACT}

In 1991, the current five-year contract DE-AC01-91FE62302 was entered into between the Office of Fossil Energy and WRI. A total contract value of $\$ 548,358.00$ was authorized, with $\$ 108,736.00$ for the Base Year and four renewable option years. The assigned tasks to be addressed by WRI have varied over the life of the contract, but the proposed statement of work has always included the following two tasks:

Task 1 Test and evaluate technologies that may be used to respond to spills of liquefied gas and other hazardous substance that threaten public health or the environment.

Task 2 Establish a technology transfer system and provide outreach related to facility activities by which WRI documents and archives spill control technology; investigates and analyzes significant hazardous spill incidents; develops and provides generic emergency action plans; documents and archives spill test results; develops emergency action plans to respond to spills; conducts training of spill response personnel; and establishes safety standards for personnel engaged in spill response activities.

These tasks are taken directly from the 1986 SARA, Section 118(n) language, but the tasks assigned by DOE have addressed only a portion of these tasks, specifically providing outreach activities related to the facility, documenting and archiving spill test results, and making this information available to the public.

The first outreach activity undertaken was the sponsorship, along with DOE-FE, EPA, the American Petroleum Institute (API), GRI, CCPS, and DRI, of the DOE Spill Test Program Forum held in Las Vegas, Nevada, June 25-26, 1991 (U.S. DOE-FE Newsletter, 1991). This meeting attracted a large audience from industry and public and private sectors.

The first-day events included an overview of the Spill Test Program; presentations by DOE program management, forum cosponsors, and past test sponsors; a discussion of Spill Test Program direction and new opportunities; lessons learned; and Q\&A sessions in which several audience members raised questions about the program and the Spill Test Facility's capabilities and made recommendations regarding future activities. On the second day of the Forum, a tour of the Spill Test Facility took place. This unique opportunity allowed the visitors to observe the STF's capabilities and equipment for testing hazardous materials.

Attendees reported that they found the Forum to be very informative and valuable. Generally, most attendees indicated that the STF was an excellent place for testing and had potential for a vast range of tests, but that meteorological capabilities were definitely needed. 
Some stated that the Forum was an excellent opportunity to exchange information among sectors. The single most noted comment was that information should be distributed about the Spill Test Facility, the program, tests, etc., through a newsletter, additional forums, exhibits, or other form and that recipients should include emergency responders, fire service, and other emergency personnel. This outreach, they noted, needed to include all tests results, whether positive or negative, so that people could be better prepared for emergency response. Several specific recommendations included:

- Maintain a higher public profile and make the test results available and accessible to public and industry.

- Recreate some recent, well-documented actual releases to test models against real events.

- Create a centralized data base for modelers or others to access.

- Form an industry/government/university committee on various subjects, such as dispersion modeling, to gain consensus. Form a federally funded information agency for transfer of information/technology.

- Conduct tests based on reactions of fire fighting agents currently used against hazardous materials and chemicals being used and transported.

- Expand the Spill Test Facility to allow fire or explosion testing (e.g., flammable liquid container, fire/unconfined vapor cloud explosion tests).

Several Spill Test Program Forum attendees showed interest in obtaining a copy of a video tape of tests conducted at the Spill Test Facility, which was shown at the Forum. DOE decided to evaluate the request before releasing the video.

As described, the original LGFSTF spill test data base was transferred from LLNL in November 1989. Other than the initial review of the data files, no other activities were conducted on these files until the current five-year contract, DE-AC01-91FE62302, was completed in September 1991. Therefore, from March 1990 until October 1991, the LGFSTF spill data base remained dormant. In fact, WRI's support and involvement in the LGFSTF spill program was decreased during this period.

Under direction from DOE-FE headquarters, WRI proceeded to prepare the LGFSTF spill test data base for posting on a WRI-maintained bulletin board system (BBS). This was broken into subtasks of: (1) identifying missing data files or portion of data files, (2) collecting copies of the relevant data reports and publications associated with the individual data sets, (3) obtaining microfiche copies of all printed documents that would accompany magnetic copies of the data, (4) obtaining permission from publishers and authors to reproduce the published documents via microfiche for interested users, (5) developing additional documentation to assist users in understanding the organization of the spill test data base, and (6) determining appropriate trade 
journals and their advertising rates and schedules for advertising the availability of the LGFSTF spill data base files.

Due to the time gap between the acquisition of the data in the data base and the addressing of the auxiliary documentation that was required to accompany the data files when distributed to the public, WRI encountered some difficulty in gaining access to the specific individuals and their associated reports to fully document the data base. Specifically, by late 1991 and early 1992, members of the LLNL team that had generated the original data files and conducted the field experiments during the late 1970 s and through the 1980 s had been reassigned to different projects or had left LLNL. In addition, certain portions of the LLNL-acquired data, i.e., still photos, video, and some three-axis meteorological data, were not included with the other data fields. Much was unavailable because the original raw data had been archived and was not recoverable without significant expense.

During the start-up of the CAAA program implemented through EPA, DOE and EPA collaborative efforts combined to request the LGFSTF spill data base. Questions regarding the quality of the LLNL dispersion data files were discussed by WRI and Dr. Albert Dietz, Contracting Officer's Technical Representative (COTR). Specifically asked, was the validity of these data sufficient that DOE-FE would want this information placed into the public domain? WRI pointed out that some of these same data had already been made available to EPA via various investigators to validate or modify mathematical models used in the public sector and accepted by EPA. DOE decided that since there was some concern about the quality of these dispersion data, WRI would concentrate on making the nondispersion data available to the public via the BBS and delay placing the LLNL dispersion data files on the BBS.

In 1993, the DOE LGFSTF site contractor for DOE, the Nevada Operations Office (NVOO) provided additional data files for field experiments conducted at the LGFSTF after the LLNL dispersion experiments, which ended in 1988. These post-1988 spill test data files were from mitigation experiments and experiments investigating source characterization, protective suit testing, and limited dispersion testing.

These tests included the following experiments identified by their sponsor:

1. Ansul - 1990, 9 tests

2. Silicone Health Council (SHC) - 1990, 13 tests

3. Dow Chemical - 1990, 6 tests

4. Center for Chemical Process Safety (CCPS) - 1990, 60 tests

5. Lawrence Livermore National Laboratory (LLNL) - 1991, 17 tests

6. Lawrence Livermore National Laboratory (LLNL) - 1992, 24 tests

7. DuPont $-1992,31$ tests

8. Desert Research Institute/Western Research Institute (DRI/WRI) - 1993, 4 tests 
Each data set contained the following information:

1. One or more files for each data acquisition system (DAS) used

2. The controlling data file for control room DAS

3. The control room check-off lists

In addition, some data sets contained text files documenting the experiment.

All available data was gathered together in a cohesive format. Programs were written to copy data from the disks provided from the STF, remove unnecessary header data, and collect multiple files from one test into one file. In all but three experiments, all of the data for a given test within a series has been grouped into one file with timestamps as row headings and sensor tag names as column headings. For the CCPS, SHC, and DRI/WRI experiments, data was acquired by multiple systems, and the data from each system was stored in a separate file. For example, during the SHC tests, data was taken by the control room system, the weather system, and the forward data acquisition system. This means there are three files for each SHC test.

The data was stored in comma separate value (CSV) text files, since CSV files can be imported easily into all leading spreadsheet, data base, and word processing systems. Additionally, storing the data as text enables excellent compression. Then the data for each test was compressed into self-extracting ZIP files for cost-effective storage and data transfer. Additionally, tests with multiple files were gathered into a single compressed file.

More than 1,600 entries were added to the bibliography. The computer services at the University of Wyoming library were used extensively and yielded a large number of relevant references, including abstracts. Additionally, citations from bibliographies of leading papers and books were added. Entries include abstracts when available and keywords. The new entries were checked to verify use of codes and formats and were merged with the old data base. The data base used was Foxpro, which allows simple inclusion of the abstracts.

A mailing list from DOE and a list of WRI contacts were combined. This list was parsed into fields, saved as a CSV file and put into a self-extracting ZIP file, which was made available on the BBS.

In September 1994, WRI was informed that funding was not available to support continued access to the LGFSTF spill data base on the BBS. In November 1994, after submitting a revised budget that addressed task cost on a monthly basis, funding for FY 95 was established at $\$ 52 \mathrm{~K}$ to support the availability of the LGFSTF spill data base and associated components on the BBS and the costs of advertising in trade journals. 
During early 1995, WRI contacted several journals and magazines to inquire about their advertising rates. Additionally, a paper (Nordin, et al., 1995) published by WRI under a separate contract to DOE in the April 1995 issue of Environmental Solutions briefly discussed the data base and the BBS.

In June 1995, WRI prepared the advertisement that appeared in Pollution Engineering, Chemical Processing, and Environmental Protection. This was forwarded to Dr. Dietz for his approval. In August 1995, WRI submitted the BBS advertisement to Environmental Protection for publication in its September, October, and November issues. WRI submitted the advertisement to Pollution Engineering and Chemical Processing in September. The advertisement ran three months, beginning in November. The submissions were staggered so the advertisement periods would not completely overlap.

In December 1996, the LGFSTF spill data base and its associated components were made available on the Internet's World Wide Web.

\section{WORK RELATED TO THE 1986 SARA TASKS}

WRI takes the intent of Congress as outlined in the 1986 SARA language very seriously. In addition to the activities accomplished under the DOE NN-60 contract just described, WRI has conducted other activities related to this mandate.

A portion of these other activities have been directed by the Congressional language in the 1990 CAAA, Section 103(f) and 901(h). In the implementation of the CAAA 112(r) regulations that direct the EPA to impose the development of Risk Management Planning (RMP) on any entity (private industry or governmental agency) that has threshold amounts of certain chemicals and petrochemicals, Congress directed that certain research and development of technologies related to the RMP mandates be conducted. WRI was named as one of the nongovernmental/ nonindustrial research institutes to conduct this research and development.

One of WRI's first activities in supporting the CAAA mandates was to attend a workshop sponsored by the EPA at Research Triangle Park (RTP), North Carolina, in July 1991. The workshop was attended by representatives from federal agencies (EPA, DOT, DOE), chemical research groups (API, GRI, CCPS), private sector industries, DRI, and WRI. The workshop was part of the implementation of the 1990 CAAA, Title IX, Section 103(f), to develop an experimental and analytical research program at the LGFSTF. 
Section 103(f) specified that the following research studies were to be conducted at the LGFSTF:

1. develop a list of chemicals

2. evaluate at least 10 chemicals per year

3. select a minimum of two chemicals for testing per year.

Priorities were to be assigned on the basis of addressing potential risk to human health from accidental release.

A proposed research plan for the LGFSTF was developed by WRI and DRI for this workshop, which included five tasks:

1. Provide a list of chemicals

2. Define source term

3. Develop and evaluate atmospheric dispersion models

4. Evaluate mitigation strategies

5. Define future research needs

During this workshop an initial list of thirteen chemicals were selected for further investigation based on their toxicity, volume transported or used in manufacturing processes, and suitability for testing at the LGFSTF. The list included other toxic chemicals from the CAAA, Section 112(r) (Chemical Accident Prevention):

1. titanium tetrachloride

2. phosphorous oxychloride

3. hydrazine

4. trimethylchlorosilane

5. ammonia

6. chlorine

7. sulfur dioxide
8. hydrogen sulfide

9. sulfur trioxide

10. hydrogen fluoride

11. hydrogen chloride

12. phosgene

13. bromine

In addition, carbon dioxide was chosen as an inert stable nontoxic gas to be used as a surrogate in initial baseline validation tests of the models.

In January 1993, WRI and DRI provided additional support to the EPA by enhancing the 1991 proposed research plan (described above) for implementing the 1990 CAAA Section 103(f). This enhanced research plan reiterated the original five tasks and in addition described the capabilities of the LGFSTF, proposed an outreach plan for the facility, and outlined the research collaborators and program management required to implement the program. 
In March 1993, the EPA Office of Research and Development entered into a contract with DRI and WRI to conduct a series of field experiment at the LGFSTF to study the behavior of hazardous spills under worst-case (stable meteorological) conditions. This allowed DRI/WRI to conduct the first carbon dioxide dispersion experiments at the LGFSTF in July 1993. This first field series tested the procedures, potential for obtaining stable conditions, and demonstration of dense gas effects with minimal release of $\mathrm{CO}_{2}$ (Egami, et al., 1996). Even though DOE-FE had mothballed the LGFSTF in 1992, a field program was successfully carried out with support from the DOE site contractor, EG\&G/EM, and significant prodding by WRI/DRI on behalf of the EPA for the CAAA experiments.

During this field program, the 24-m meteorological tower located on site was instrumented, and sufficient data was collected during the three-week field study to document that stable meteorological conditions could be obtained on a predictable basis during certain periods under the proper macro-meteorological conditions. In July 1993, DRI started collecting and archiving meteorological data from the 24-m meteorological tower on a year-round basis to assist not only the EPA CAAA research program but also other field programs using the LGFSTF location (Coulombe, et al., 1995A, 1995B, 1995C).

A portion of the CAAA, Section 103(f) language directed the investigation of ten chemicals per year and the testing of at least two chemicals per year. As part of this direction, WRI designed a series of evaporation experiments to be conducted in the LGFSTF wind tunnel to study the source characterization of two widely produced and hazardous chemicals, ammonia and chlorine. It was planned that these experiments would be conducted in 1994, but scheduling and funding problems delayed the work until the spring of 1995. In late March and early April, WRI conducted these evaporation experiments, which were observed by representatives from DOE, EPA, the National Oceanic and Atmospheric Administration (NOAA), and the University of Arkansas.

The experiments did not go as anticipated; the formation of chlorohydrate during the chlorine experiments caused significant problems in the transfer of the liquid chlorine from the supply portion of the apparatus to the measurement portion of the apparatus. While the formation of chlorohydrate was a known phenomenon, its rate of formation in the relatively dry desert climate was not expected to cause as serious a problem as actually occurred. The ammonia experiments were conducted with the experimental apparatus modified slightly, and reasonable evaporation rates were measured for one set of conditions. Fewer conditions were tested than planned because of damage to the experimental apparatus caused by the chlorine experiments and a reduction in site access time resulting from the scheduling of another client. 
A third field test program, funded in part by the EPA Chemical Emergency Preparedness and Prevention Office (EPA-CEPPO), EPA-ORD, WRI through its jointly sponsored research program with DOE-FE, and the PERF Project 93-16, involved a study of the dispersion of a surrogate $\left(\mathrm{CO}_{2}\right)$ dense gas under neutral to very stable conditions using three different surface roughness regimes during August and September 1995. This research program (referred to as the Kit Fox series) was also carried out at the LGFSTF. This field demonstration involved 107 releases ranging from finite duration (20 second) to continuous (2-7 minute) releases under neutral to stable meteorological conditions.

The design for the Kit Fox series was based on: (1) the July 1993 EPA CAAA experiments conducted by DRI/WRI, (2) the WRI analysis of the 24-m meteorological tower data collected and archived by DRI from July 1993 to September 1994, (3) previous wind tunnel studies sponsored by the American Petroleum Institute (API), and (4) mathematical model (HEGADAS $\mathrm{v} 3+$ ) predictions. The certification and analysis of these data are still in progress but preliminary analysis indicates that this field study will provide significant insight and understanding into the behavior of dense gas plumes as required by the 1990 CAAA Section 112(r) worst-case scenario. Unfortunately, EPA-ORD elected to discontinue the funding of the 1990 CAAA mandated research program as of October 1995, which has contributed to the delay in certification and analysis of the Kit Fox data.

The Kit Fox field experiment and the manner in which it was conducted demonstrate two important points related to this type of research program. First, it is possible, although not easy, for industrial concerns and governmental agencies to conduct collaborative research programs that benefit all parties. Second, the Kit Fox experiment was considerably more complex in its funding and management structure than necessary, and only with considerable motivation and perseverance was the project accomplished. (Certification and analysis are yet to be finished.) As Figure 1 demonstrates, the number of parties involved was substantial, and the flow of sponsoring funds (depicted by arrows) was difficult to grasp without being continually involved. At times, the objectives and agendas for different sponsors conflicted, which was to be expected. While it was difficult to satisfy all parties, collaboration provided a more balanced approach to the issues being investigated, so that a significant and well thought-out design was developed.

The entire process could have been streamlined if the funding had been broken into two sources, industrial and governmental, with specific decision-making authority delegated in some manner that ensured that no party's objectives or agenda was ignored or completely overruled. However, the specifics of the structure of this research program are not more important than the fact that this research program must be moved forward with commitment and diligence commensurate with that which Congress has shown toward these activities as they relate to the public safety. 


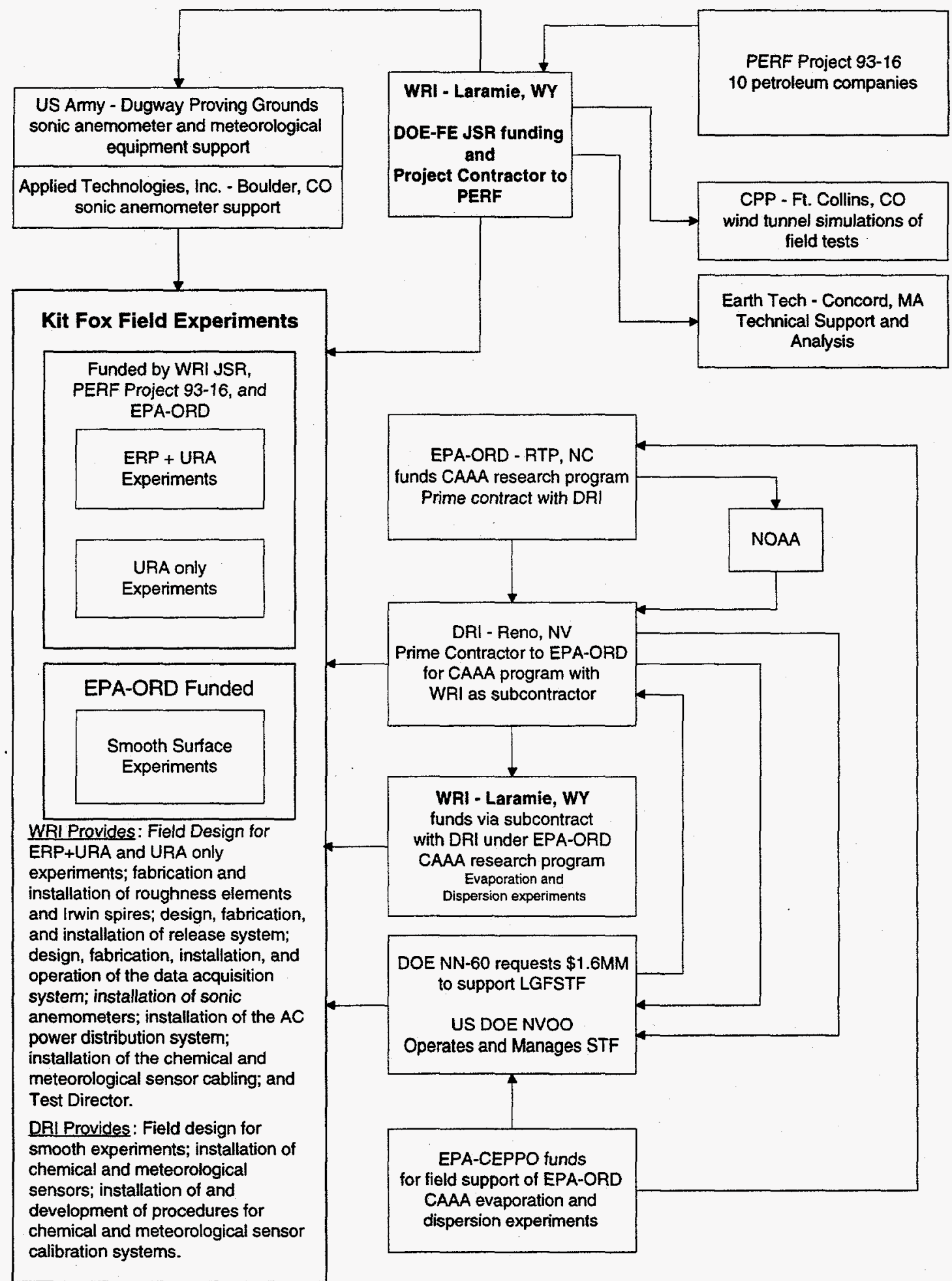

Figure 1 - Kit Fox Field Experiment Structure 
A requirement for conducting each of the three EPA CAAA field research projects at the LGFSTF was the preparation of three separate documents, Test Plan, Test Management Summary, and Safety Assessment Document, for each test series. The specifications for the required documents are provided by DOE (U.S. DOE, 1994). Each of these documents was reviewed and approved by DOE and DOE-NVOO, then DOE selected contractors to ensure that proper and appropriate design, management, and safety considerations had been performed before it granted permission to proceed with the field experiments (WRI/DRI, 1993a, 1993b, 1993c, 1995a, 1995b, 1995c, 1995d, 1995e, and 1995f).

Finally, in heeding the Congressional direction to conduct technology transfer, WRI's Emergency Response Technology Group had identified a need in the public sector for rapid and easy access to information and predictive capability for responding to releases of hazardous materials. With in-house funding and support, WRI has developed a commercial product that addresses the needs of the emergency responder. WRI's palmtop computer application combines information from a number of sources, including a portion of the STF data base. It provides a simple, effective method for the responder on the scene to enter incident-specific information and compute appropriate downwind evacuation distances to ensure the safety of personnel and the public.

This portable and easy-to-use device is the first product of its type to be made available to the public sector. Its development was in part an outgrowth of WRI's access to the LGFSTF spill data base and experience gained conducting a field research program that investigated the behavior of surrogate dense gas $\left(\mathrm{CO}_{2}\right)$ releases to emulate accidental spills of hazardous substances. The product's existence and continuing acceptance within the emergency response public sector provides a future vehicle/platform for the transfer of emergency response technology developed by DOE, EPA, DOT, and other federal agencies to the specific personnel and organizations for which these technologies are being developed.

\section{ANTICIPATED REQUIREMENTS FOR FUTURE ACTIVITIES}

The need for developing the technology and methodology for responding to hazardous material releases has been documented in the previous discussions. The WRI activities under the reported contract have addressed only a minor portion of the Congressional intent. If DOE intends to significantly increase its level of commitment to address the 1986 SARA Section 118(n) language, then WRI recommends that specific activities be incorporated into the scope of work. These recommended research activities are not exclusively WRI's; they represent a consensus of governmental, academic, and industrial concern. 
In an effort to focus research programs and coordinate efforts, agencies of the federal government in cooperation with private industry and some European concerns have formed the Forum for Hazard Assessment Research (FHAR). The FHAR includes representatives from the DOE, EPA, DOT, FEMA, AIChE's CCPS, API, the Chemical Manufacturers Association (CMA), representatives from industrial chemical and petrochemical manufacturing companies, and representatives from universities and affiliated research organizations. The FHAR addresses current research efforts and the basis for future research programs funded and directed by each of the organizations represented. At a meeting February 6-7, 1996, an effort was made to identify the research needs in the field of hazardous material releases based on the current state of research programs. The primary areas are listed in Table 2 .

\section{Table 2. Future Needs}

\begin{tabular}{|l|}
\hline Buoyancy \\
\hline Mitigation* \\
\hline Aerosols* \\
\hline Surface Roughness* \\
\hline Source Characterization \\
\hline Concentration Fluctuations* \\
\hline Stable Conditions* \\
\hline Short Duration* \\
\hline Near Field Dispersion \\
\hline Fire and Explosion \\
\hline Model Evaluation* \\
\hline * Denotes that some work has been done or is underway \\
in this area.
\end{tabular}

Some of these areas are specifically identified by the authorization language in the 1986 SARA and 1990 CAAA legislation. WRI recommends using this list to provide a framework for future research activities if there should be a significant increase in the level of commitment to address the 1986 SARA Section 118(n) language.

Some of these topics can be investigated with the existing facilities at the LGFSTF with only minor additions to the facilities. Others, such as the investigation of buoyancy, aerosols, and fire and explosions, may require additional capabilities or facilities not currently available at the LGFSTF. Significant savings can be achieved by addressing the areas of research that don't require additional facilities at the LGFSTF, for example, by using $\mathrm{CO}_{2}$ as the surrogate dense gas and minimizing the purchase of additional equipment. Studying more than one of these research areas with a single field program can be accomplished with proper design and planning. For instance, near-field dispersion and concentration fluctuations can be investigated under varying 
meteorological conditions, including stable conditions. Specifically, this could be done using $\mathrm{CO}_{2}$ as the surrogate dense gas with instrumentation similar to that used and proven during the Kit Fox field experiments conducted in August and September 1995.

Another field research program could be designed to address source characterization by studying the factors that directly influence the source emission. WRI has previously conducted evaporation experiments with single components where the material is in a single phase (liquid), but additional research is required to focus on multiple-component pools and systems where twophase releases are involved. Some of this work could be conducted in the partially controlled environment of the wind tunnel located at the LGFSTF, and some could be conducted in the uncontrolled confines of Frenchman Flat.

\section{CONCLUSIONS}

During the course of the five-year contract DE-AC01-91FE62302, WRI has implemented a portion of the 1986 SARA, Section 118(n) language. A portion of the LGFSTF spill data base has been made available to the public, along with accompanying documentation and auxiliary information. To make the data base more inclusive, the bibliography has been expanded by $200 \%$. This has been augmented by inclusion of the DOE and WRI mailing lists of parties that have demonstrated an interest in hazardous material spill technology. The availability of the data base on either the BBS or the Internet has been advertised in trade journals directed toward individuals and organizations with an interest in such information.

Additional tasks implementing the mandates of the SARA language still have not been addressed. Only with an increased commitment of funding and direction from DOE NN-60 can these tasks be approached. WRI has continued, under EPA's CAAA program, to focus on activities with collaborative partners to address research needs that are directed at public safety concerns. With EPA-ORD's decision to terminate the DRI/WRI funding in October 1995, the funding of these other related activities appears to be ordained to meet the same fate as the SARA language mandates. They will receive minimal, if any, support. The problem is not that the research programs to develop emergency response technologies have not been adequately authorized or directed by Congress, rather the problem is funding the designated entities at levels that prevents these programs from going forward.

In spite of the past and apparent future level of commitment by DOE and EPA, WRI has taken the position that the identification of public needs and the transfer of currently available technology to meet these needs, as outlined by Congress, can be achieved with focus of efforts. Through development of its palmtop computer application, WRI has undertaken to transfer the 
knowledge it has gained to the public, specifically to the emergency responders who are charged with managing hazardous material spills. This commercial product provides a means (possibly an ideal means) for funneling future emergency response technology to the public sector responsible for dealing with real-world emergency incidents.

If funding from DOE or EPA is forthcoming, WRI has identified specific field research projects that will further address the SARA and CAAA language. These are not projects proposed or conceived by WRI alone, but represent a consensus of industry, government agencies, and other entities concerned about the consequences to workers and the public from spills of hazardous materials. 


\section{REFERENCES}

Blewitt, D.N., J.F. Yohn, R.P. Koopman, and T.C. Brown, Conduct of Anhydrous Hydrofluoric Acid Spill Experiments, Amoco Corporation, Chicago, IL and Lawerence Livermore National Laboratory, Livermore, CA, Paper presented at the International Conference on Vapor Cloud Modeling, Boston, MA, Nov. 2-4, 1987.

Chilson, V., D.C. Sheesley, and J. Diamond, 1989, Spill-Related Bibliography for the Liquefied Gaseous Fuels Spill Test Facility. Laramie, WY, WRI Bibliographic Listing.

Coulombe, W., J. Bowen, D. Freeman, R. Egami, B. Cristani, S. Schmidt, D. Sheesley, B. King, T. Routh, 1995, 24m Meteorological Tower Data Report-Period: August Through December, 1993, Reno, NV, DRI Document No. 94-3305.F.

Coulombe, W., J. Bowen, D. Freeman, R. Egami, B. Cristani, S. Schmidt, D. Sheesley, B. King, T. Routh, 1995, 24m Meteorological Tower Data Report-Period: January Through March, 1994, Reno, NV, DRI Document No. 95-3501.2F.

Coulombe, W., J. Bowen, D. Freeman, R. Egami, B. Cristani, S. Schmidt, D. Sheesley, B. King, T. Routh, 1995, 24m Meteorological Tower Data Report—Period: April Through June, 1994, Reno, NV, DRI Document No. 95-3501.3F.

Egami, R., W. Coulombe, J. Bowen, D. Freeman, J. Watson, D. Koracin, D. Schorran, B. Zielinska, D. Sheesley, J. Nordin, T. Routh, B. King, 1996, Characterization of Carbon Dioxide Releases-Experiment One, Reno, NV, DRI Document No. 93-3305.3F.

Kling, G.W., M.A. Clark, H.R. Campton, J.D. Devine, W.C. Evans, A.M. Humphrey, E.J. Koenigsberg, J.P. Lockwood, M.L. Tuttle and G.N. Wagner, The 1986 Lake Nyos gas disaster in Cameroon, West Africa, Science, April 10, 1987, pp. 169-175.

Leone, F.A, Hazardous Materials Testing at the U.S. Department of Energy's Liquefied Gaseous Fuels Spill Test Facility, Presented at the AIChE meeting, August 20-23, 1989.

Leone, F.A, Hazard Materials Testing at the U.S. Department of Energy's Liquefied Gaseous Fuels Spill Test Facility, Plant/Operations Progress, Vol. 9, No. 4, October 1990.

Nordin, J.S., and D.C. Sheesley, 1989, Survey of 123 Toxic Chemical Release Accidents in the United States and Applicability to Future Development of Department of Energy Nevada Spill Test Facility Programs. Laramie, WY, WRI Report to DOE, WRI-89-R054.

Nordin, J.S., and D.C. Sheesley, S.B. King, and T.K. Routh, Chemical-Spill Tests Foster Improved Air Pollution Control Technologies. Environmental Solutions, April 1995.

Sheesley, D.C. and J.L. Diamond, The Development of a Collaborative R\&D Program for the Liquefied Gaseous Fuels Spill Test Facility (LGFSTF), Laramie, WY, WRI Final Report to DOE, WRI-90-R064, December 1990. 
Tickner, J.A. and H. Gray, Accidents Do Happen, National Environmental Law Center (Boston, MA) and United States Public Interest Research Group (Washington, DC), August 1994.

U.S. Department of Energy-Office of Fossil Energy, Spill Test Program Newsletter, No.1, August 1991.

U.S. Department of Energy-Office of Fossil Energy, Environmental Assessment for Hazardous Materials Testing at the Liquefied Gaseous Fuels Spill Test Facility, Final Report, DOE-EA0864, November 1994.

WRI/DRI, Characterization of Stable and Baseline Meteorological Conditions at the STF Using Carbon Dioxide—Test Plan, March 1993.

WRI/DRI, Characterization of Stable and Baseline Meteorological Conditions at the STF Using Carbon Dioxide-Test Management Summary, March 1993.

WRIDRI, Characterization of Stable and Baseline Meteorological Conditions at the STF Using Carbon Dioxide-Safety Assessment Document, March 1993.

WRI/DRI, Chlorine and Ammonia Evaporation Rate Measurements from Evaporation Pans in the STF Wind Tunnel-Test Plan, March 1995.

WRI/DRI, Chlorine and Ammonia Evaporation Rate Measurements from Evaporation Pans in the STF Wind Tunnel-Test Management Summary, March 1995.

WRI/DRI, Chlorine and Ammonia Evaporation Rate Measurements from Evaporation Pans in the STF Wind Tunnel-Safety Assessment Document, March 1995.

WRI/DRI, Characterization of Dense Gas Dispersion in the Presence of Obstacles and Roughness Elements-Test Plan, June 1995.

WRI/DRI, Characterization of Dense Gas Dispersion in the Presence of Obstacles and Roughness Elements-Test Management Summary, June 1995.

WRIDRI, Characterization of Dense Gas Dispersion in the Presence of Obstacles and Roughness Elements-Safety Assessment Document, June 1995. 